\title{
ĐẶC ĐIỂM BỎNG NGƯờI LỚN VÀ THÁCH THỨC TRONG ĐIỀU TR!
}

\author{
Mai Xuân Thảo, Ngô Minh Đức, Chu Anh Tuấn, Lê Quốc Chiểu \\ Bệnh viện Bỏng Quốc gia Lê Hũu Trác
}

\section{TÓM TẮT}

Mục tiêu: Đánh giá đặc điểm bị bỏng, kết quả điều trị và các thách thức gặp phải trong điều trị bỏng người lớn tại Bệnh viện Bỏng Quốc gia.

Đối tượng và phương pháp nghiên cứu: Nghiên cứu hồi cứu dữ liệu ở bệnh nhân bỏng người lớn điều trị tại Bệnh viện Bỏng Quốc gia từ tháng 1/2008 đến tháng 12/2017.

Kết quả: Tỷ lệ nam/nữ là 2,7/1, bệnh nhân đến từ nông thôn chiếm $72,36 \%$ chủ yếu không có BHYT (58,51\%). Lứa tuổi bị bỏng chủ yếu từ 20 - 39 tuổi $(63,83 \%)$. Tác nhân bỏng thường gặp nhất là nhiệt khô sau đó đến bỏng điện (56,91\% và $24,8 \%)$. Diện tích bỏng trung bình là $9 \%$ diện tích cơ thể - DTCT (diện tích bỏng từ $3-20 \%$ DTCT) và diện tích bỏng sâu trung bình từ 0 - 4\% DTCT, số bệnh nhân bỏng hô hấp chiếm tỷ lệ 3,83\%, bệnh nhân bỏng kèm chấn thương kết hợp là 0,94\%.

Ngày điều trị trung bình là 12 ngày (ngày nằm điều trị từ 7 - 23 ngày). Bỏng do điện kéo dài ngày điều trị nhất, sau đến bỏng do nhiệt khô. Bỏng hô hấp có tỷ lệ tử vong $75,1 \%$. Chỉ số LA50 của diện tích bỏng chung là $64,26 \%$, chỉ số LA50 của diện tích bỏng sâu là 35,68\%. Bỏng điện, bỏng nhiệt khô là nguyên nhân gây bỏng rộng, bỏng sâu kèm theo tỷ lệ chấn thương kết hợp và bỏng hô hấp cao hơn với tỷ lệ tử vong chung là 4,6\%. Tỷ lệ tử vong ở bệnh nhân không có BHYT cao hơn khi bỏng nhiệt khô, bỏng điện, bỏng hô hấp kèm theo chấn thương kết hợp.

Kết luận: Trong điều trị bỏng người lớn, đặc biệt bỏng nhiệt khô và bỏng điện còn nhiều thách thức với số lượng lớn bệnh nhân bị nặng khiến ngày nằm điều trị dài hơn, tỷ lệ tử vong cao. Ngoài ra cũng phải kể đến ảnh hưởng của BHYT.

Từ khóa: Bỏng người lớn, thách thức, điều trị, tử vong.

\begin{abstract}
$_{1}$
Aims: Investigating characteristics, outcome and the treatment challenges of adult burn patients.

Subjects and methods: A retrospective study was conducted on data of adult burn patients admitted to National Burns Hospital from the 2008 year to the 2017 year.
\end{abstract}

Chịu trách nhiệm: Ngô Minh Đức, Bệnh viện Bỏng Quốc gia Lê Hữu Trác

Email: yducqy@gmail.com

Ngày nhận bài: 10/7/2021; Ngày phản biện: 09/8/2021; Ngày duyệt bài: 31/8/2021 
Results: The male to female ratio was 2.7/1. Patients from rural areas accounted for 72.36\%. Almost all adult burn patients had not the health insurance (58.51\%). The most common age group was 20 to 39 years old (63.83\%). Dry heat and electricity are the most common causes of burns, at $56.91 \%$ and $24.8 \%$, respectively. The mean area burned was 9\% (3 - 20\%) total body surface area (TBSA), the average area of deep burns was $0-4 \%$ TBSA. The percentage of patients with respiratory burns was $3.83 \% .0 .94 \%$ was the figure for combined injury.

The length of hospital stay (LOS) is 12 days ( from 7 - 23 days). Electrical burns last most treatment days, followed by dry heat burns. The death rate of inhalation injury patients was $75.1 \%$. The LA50 index (Lethal area 50 index) was $64.26 \%$, the LA50 of deep burns was $35.68 \%$. Electrical and dry heat burns were the cause of broader burns, more extensive burn areas, and have a higher combined injury rate and a higher rate of respiratory burns. Overall mortality was $4.6 \%$, mortality rates were higher in uninsured, dry heat burns, electrical burns, respiratory burns, and combined trauma.

Conclusion: There are still many challenges in the treatment of adult burns, especially dry heat burn and electricity burn are large challenges of treatments, which cause longer hospital stays and high mortality rates. In addition, health insurance must also be mentioned.

Keywords: Adult burns, challenges, outcomes, death

\section{1. ĐĂT VẤN $\boxminus E \hat{~}$}

Người lớn là người độ tuổi từ 16 đến dưới 60 tuổi. Người lớn về giải phẫu, sinh lý, tâm sinh lý, chức năng sinh học đã ổn định, khác đặc điểm trên so với lứa tuổi khác, đủ sức khỏe để lao động sản xuất, là lực lượng lao động, sản xuất chính của xã hội, tham gia nhiều loại hình kinh tế và môi trường lao động khắc nghiệt, vì vậy khi tai nạn bỏng xảy ra thường bị bỏng nặng, khiến công tác điều trị khó khăn và để lại hậu quả nặng nề.

Nghiên cứu ở nhóm lứa tuổi này bị bỏng đã được báo cáo ở nhiều nơi trên thế giới quan tâm đến. Ở người lớn, nguyên nhân và nguy cơ bị bỏng cao hơn so với lứa tuổi khác. Mặt khác, chế độ chính sách và tài chính đối với nhóm đối tượng này cũng khác so với nhóm còn lại. Chính vì vậy vấn đề điều trị bỏng cho đối tượng này cũng khác, có thể khó khăn hơn. Nghiên cứu này nhằm mục tiêu nêu lên những đặc điểm bị bỏng, kết quả điều trị và các thách thức gặp phải trong điều trị bỏng người lớn, từ đó có các kiến nghị dự phòng và chăm sóc điều trị bỏng được tốt hơn.

\section{2. ĐỐI TƯợNG VÀ PHƯƠNG PHÁP NGHIÊN CỨU}

\section{1. Đối tượng nghiên cứu}

Bệnh nhân bị bỏng điều trị tại Bệnh viện Bỏng Quốc gia có độ tuổi từ 16 đến dưới 60 tuổi trong 10 năm, từ năm 2008 - 2017.

\subsection{Phương pháp nghiên cứu}

Nghiên cứu hồi cứu, thống kê mô tả có phân tích. Các chỉ tiêu về đặc điểm, kết quả điều trị bệnh nhân bỏng người lớn được thu thập: Tuổi, giới, nơi bị bỏng, bảo hiểm y tế (BHYT), diện tích bỏng chung, diện tích bỏng sâu (tính theo \% tổng diện tích cơ thể - DTCT), bỏng hô hấp, chấn thương kết 
hợp, các biến chứng, số lần phẫu thuật, ngày điều trị, tử vong hoặc cứu sống.
- Phân loại tổn thương bỏng theo phân loại của Hiệp hội Bỏng Hoa Kỳ [1]

Bảng 2.1. Phân loại mức độ bỏng của Hiệp hội Bỏng Hoa Kỳ

\begin{tabular}{|l|l|l|}
\hline \multicolumn{1}{|c|}{ Bỏng nhẹ } & \multicolumn{1}{|c|}{ Bỏng vừa } & \multicolumn{1}{c|}{ Bỏng nặng } \\
\hline Người lớn bỏng < 10\% DTCT & Người lớn $10-20 \%$ DTCT & Người lớn > 20\% DTCT \\
\hline $\begin{array}{l}\text { Trẻ em hoặc người già bỏng }< \\
5 \% \text { DTCT }\end{array}$ & $\begin{array}{l}\text { Trẻ em hoặc người già bỏng } \\
5-10 \% \text { DTCT }\end{array}$ & $\begin{array}{l}\text { Trẻ em hoặc người già bỏng > 10\% } \\
\text { DTCT }\end{array}$ \\
\hline$<2 \%$ DTCT bỏng sâu & $2-5 \%$ DTCT bỏng sâu & $>5 \%$ DTCT bỏng sâu \\
\hline & Bỏng điện hạ thế & Bỏng điện cao thế \\
\hline & Nghi ngờ bỏng hô hấp & Bỏng hô hấp \\
\hline & Bỏng chu vi & $\begin{array}{l}\text { Bỏng mă̆t, khớp, bàn tay hoặc bàn chân, } \\
\text { bỏng mắt, bỏng hoa chất. }\end{array}$ \\
\hline & Bệnh lý kèm theo & Chấn thương kèm theo \\
\hline
\end{tabular}

* Xử lý số liệu: Số liệu được phân nhóm, tính các chỉ số về số lượng, tỷ lệ, giá trị trung bình. So sánh các giá trị tỷ lệ giữa hai nhóm tử vong và cứu sống để tìm mối tương quan bằng kiểm định $X^{2}$. Dùng phép kiểm định Kolmogorov-Smirnov để nhận biết phân phối chuẩn của các biến, so sánh giá trị trung bình của các biến phân phối chuẩn bằng kiểm định T-stutent,với biến phân phối không chuẩn giá trị trung bình được kiểm định phi tham số.

Số liệu được xử lý trên phần mềm SPSS 16.0, giá trị $p<0,05$ được coi là có ý nghĩa thống kê.

\section{KẾT QUÅ}

Bảng 3.1. Đặc điểm bệnh nhân bỏng người lớn nhập viện $(n=13.461)$

\begin{tabular}{|c|c|c|c|}
\hline \multicolumn{2}{|c|}{ Đặc điểm } & Số lượng & Tỷ lệ (\%) \\
\hline \multirow{2}{*}{ Giới tính } & Nam & 9.853 & $73,20 \%$ \\
\hline & Nữ & 3.608 & $26,80 \%$ \\
\hline \multirow{2}{*}{ Nơi chốn } & Thành thị & 3.721 & $27,64 \%$ \\
\hline & Nông thôn & 9.740 & $72,36 \%$ \\
\hline \multirow{2}{*}{$\mathrm{BHYT}$} & Có & 5.585 & $41,49 \%$ \\
\hline & Không & 7.876 & $58,51 \%$ \\
\hline \multirow{4}{*}{ Tác nhân } & Điện & 3.339 & $24,80 \%$ \\
\hline & Hóa chất & 348 & $2,59 \%$ \\
\hline & Nhiệt khô & 7.660 & $56,91 \%$ \\
\hline & Nhiệt ướt & 2.114 & $15,70 \%$ \\
\hline \multirow{5}{*}{ Tuổi } & 16 đến 19 tuổi & 915 & $6,80 \%$ \\
\hline & 20 đến 29 tuổi & 4.876 & $36,22 \%$ \\
\hline & 30 đến 39 tuổi & 3.716 & $27,61 \%$ \\
\hline & 40 đến 49 tuổi & 2.332 & $17,32 \%$ \\
\hline & 50 đến 59 tuổi & 1.622 & $12,05 \%$ \\
\hline
\end{tabular}


Nhận xét: Có 13.461 bệnh nhân bỏng người lớn điều trị trong 10 năm (từ năm 2008 - 2017). Tỷ lệ Nam/Nữ = 2,7/1 (9853/3608); bệnh nhân đến từ nông thôn nhiều hơn thành thị $(72,36 \%$ thành thị và $27,64 \%$ nông thôn), bệnh nhân không được hỗ trợ kinh phí từ BHYT hay ngân sách (quân nhân) là chủ yếu $(58,51 \%)$. Nguyên nhân bỏng cao nhất là nhiệt khô $(56,91 \%)$, tiếp đến là điện $(24,8 \%)$, nhiệt ướt $(15,7 \%)$, hóa chất $(2,59 \%)$. Nhóm ngành nghề bị bỏng cao là nông dân, làm tự do và công nhân. Nhóm tuổi bị bỏng cao nhất từ $20-29$ tuổi, tiếp theo là từ $30-39$ tuổi $(36,22 \%$ và $27,61 \%)$. Bệnh nhân vào điều trị bỏng nặng chiếm tỷ lệ cao nhất $37,53 \%$, bỏng vừa thấp nhất là $29,49 \%$.

Bảng 3.2. Đặc điểm tổn thương bỏng

\begin{tabular}{|l|l|c|}
\hline \multicolumn{2}{|c|}{ Đặc điểm } & Kết quả \\
\hline \multirow{5}{*}{ Diện tích bỏng chung } & Từ 0 - 19\% DTCT & $9.810(72,88 \%)$ \\
\cline { 2 - 3 } & Từ 20 - 39\% DTCT & $2.247(16,69 \%)$ \\
\cline { 2 - 3 } & Từ 40 - 59\% DTCT & $773(5,74 \%)$ \\
\cline { 2 - 3 } & Từ 60\% DTCT trở lên & $631(4,69 \%)$ \\
\cline { 2 - 3 } & Trung vị (\% DTCT) & $9(3-20)$ \\
\hline \multirow{5}{*}{ Diện tích bỏng sâu } & Bỏng nông & $6.427(47,75 \%)$ \\
\cline { 2 - 3 } & Dưới 09\% DTCT & $5.094(37,84 \%)$ \\
\cline { 2 - 3 } & Từ 10 - 39\% DTCT & $1.472(10,94 \%)$ \\
\cline { 2 - 3 } & Từ 40 - 59\% DTCT & $284(2,11 \%)$ \\
\cline { 2 - 3 } & Từ 60\% DTCT trở lên & $184(1,37 \%)$ \\
\cline { 2 - 3 } & Trung vị (\% DTCT) & $0(0-4)$ \\
\hline \multirow{3}{*}{ Mức độ } & Nhẹ & $4.440(33 \%)$ \\
\cline { 2 - 3 } & Vừa & $3.969(29,5 \%)$ \\
\cline { 2 - 3 } & Nặng & $5.052(37,5 \%)$ \\
\hline Bỏng hô hấp & $515(3,83 \%)$ \\
\hline Chấn thương kết hợp & $139(0,94 \%)$ \\
\hline Eược phẫu thuật & $6.269(46,6 \%)$ \\
\hline Số lần phẫu thuật trung bình/bỏng sâu & $0(0-2)$ \\
\hline Số ngày điều trị & & $12(7-23)$ \\
\hline Tử vong & & $662(4,6 \%)$ \\
\hline
\end{tabular}

Nhận xét: Diện tích bỏng trung bình là 9\% DTCT (bỏng từ 3 - 20\% DTCT), bỏng sâu là $0-4 \%$ DTCT. Bệnh nhân vào điều trị bị bỏng nặng chiếm tỷ lệ cao nhất 37,5\%, bỏng vừa thấp nhất là 29,5\%. Bệnh nhân được phẫu thuật chiếm 46,6\% bệnh nhân bỏng và chiếm $89,12 \%$ tổng số bệnh nhân bỏng sâu. Bỏng hô hấp chiếm 3,83\%, bệnh nhân có chấn thương kết hợp là $0,94 \%$. Có 662 bệnh nhân tử vong chiếm 4,9\%. 
Bảng 3.3. Mức độ bỏng theo các yếu tố

\begin{tabular}{|c|c|c|c|c|c|}
\hline \multirow{2}{*}{\multicolumn{2}{|c|}{ Yếu tố }} & \multicolumn{3}{|c|}{ Mức độ bỏng } & \multirow{2}{*}{$\mathbf{p}$} \\
\hline & & \multirow{2}{*}{$\begin{array}{c}\text { Nhẹ } \\
1.444 \\
(38,8 \%) \\
\end{array}$} & \multirow{2}{*}{$\begin{array}{c}\text { Vừa } \\
1.098 \\
(29,5 \%) \\
\end{array}$} & \multirow{2}{*}{$\begin{array}{c}\text { Nặng } \\
1.179 \\
(31,7 \%) \\
\end{array}$} & \\
\hline \multirow{2}{*}{ Nơi ở } & Thành thị & & & & \multirow{2}{*}{$<0,001$} \\
\hline & Nông thôn & $\begin{array}{c}2.996 \\
(30,8 \%) \\
\end{array}$ & $\begin{array}{c}2.871 \\
(29,5 \%) \\
\end{array}$ & $\begin{array}{c}3.873 \\
(39,7 \%) \\
\end{array}$ & \\
\hline \multirow{2}{*}{ Nhóm tuổi } & 16 - 30 tuổi & $\begin{array}{c}2.171 \\
(34,4 \%)\end{array}$ & $\begin{array}{c}1.854 \\
(29,4 \%)\end{array}$ & $\begin{array}{c}2.292 \\
(36,2 \%)\end{array}$ & \multirow{2}{*}{$<0,01$} \\
\hline & 31 - 59 tuổi & $\begin{array}{c}2.269 \\
(31,8 \%) \\
\end{array}$ & $\begin{array}{c}2.115 \\
(29,6 \%) \\
\end{array}$ & $\begin{array}{c}2.760 \\
(38,6 \%) \\
\end{array}$ & \\
\hline \multirow{4}{*}{ Nhóm nguyên nhân } & Điện & $\begin{array}{c}627 \\
(18,8 \%)\end{array}$ & $\begin{array}{c}938 \\
(28,1 \%)\end{array}$ & $\begin{array}{c}1.774 \\
(53,1 \%)\end{array}$ & \multirow{4}{*}{$<0,001$} \\
\hline & Hóa chất & $\begin{array}{c}158 \\
(45,4 \%) \\
\end{array}$ & $\begin{array}{c}97 \\
(27,9 \%)\end{array}$ & $\begin{array}{c}93 \\
(26,7 \%) \\
\end{array}$ & \\
\hline & Nhiệt ướt & $\begin{array}{c}977 \\
(46,2 \%)\end{array}$ & $\begin{array}{c}747 \\
(35,3 \%)\end{array}$ & $\begin{array}{c}390 \\
(18,4 \%)\end{array}$ & \\
\hline & Nhiệt khô & $\begin{array}{c}2.678 \\
(35,2 \%)\end{array}$ & $\begin{array}{c}2.142 \\
(28,1 \%)\end{array}$ & $\begin{array}{c}2.795 \\
(36,7 \%)\end{array}$ & \\
\hline \multirow{2}{*}{ Giới } & Nam & $\begin{array}{c}2.962 \\
(30,1 \%)\end{array}$ & $\begin{array}{c}2.806 \\
(28,5 \%)\end{array}$ & $\begin{array}{c}4085 \\
(41,5 \%)\end{array}$ & \multirow{2}{*}{$<0,001$} \\
\hline & Nữ & $\begin{array}{c}1478 \\
(41,0 \%)\end{array}$ & $\begin{array}{c}1.163 \\
(32,2 \%)\end{array}$ & $\begin{array}{c}967 \\
(26,8 \%)\end{array}$ & \\
\hline \multirow{2}{*}{ BHYT } & Có & $\begin{array}{c}1.793 \\
(32,1 \%)\end{array}$ & $\begin{array}{c}1.601 \\
(28,7 \%)\end{array}$ & $\begin{array}{c}2.191 \\
(39,2 \%)\end{array}$ & \multirow{2}{*}{$<0,01$} \\
\hline & Không & $\begin{array}{c}2.647 \\
(33,6 \%)\end{array}$ & $\begin{array}{c}2.368 \\
(30,1 \%)\end{array}$ & $\begin{array}{c}2.861 \\
(36,3 \%)\end{array}$ & \\
\hline
\end{tabular}

Nhận xét: Mức độ nặng của bệnh điện, bỏng nhiệt khô có tỷ lệ bỏng nặng nhân bị bỏng có sự khác biệt theo các đặc cao nhất, các nguyên nhân còn lại thì bỏng điểm dịch tễ nơi ở, nhóm tuổi, nguyển nhẹ cao hơn cả $(p<0,01)$.

nhân, giới và đối tượng. Bệnh nhân bỏng

Bảng 3.4. Tổn thương bỏng theo nguyên nhân

\begin{tabular}{|c|c|c|c|c|c|c|}
\hline \multicolumn{2}{|c|}{ Đặc điểm } & Điện & Nhiệt khô & Hóa chất & Nhiệt ướt & $\mathbf{p}$ \\
\hline \multicolumn{2}{|c|}{ Diện tích bỏng chung } & $\begin{array}{c}6(2-15) \\
(n=3.339)\end{array}$ & $\begin{array}{c}11(4-25) \\
(\mathrm{n}=7.660)\end{array}$ & $\begin{array}{c}4,5(2-11) \\
(\mathrm{n}=248)\end{array}$ & $\begin{array}{c}8(4-15) \\
(n=2.114)\end{array}$ & $<0,001$ \\
\hline \multicolumn{2}{|c|}{ Diện tích bỏng sâu } & $1,00(0-5)$ & $0(0-5)$ & $0(0-2)$ & $0(0-1)$ & $<0,001$ \\
\hline \multirow{2}{*}{$\begin{array}{c}\text { Số } \\
\text { lượng } \\
\text { bỏng } \\
\text { sâu }\end{array}$} & $\begin{array}{c}\text { Tỷ lệ theo } \\
\text { nguyên nhân }\end{array}$ & $\begin{array}{c}2.395 \\
(71,73 \%) \\
\end{array}$ & $\begin{array}{c}3.872 \\
(50,66 \%)\end{array}$ & $\begin{array}{c}143 \\
(41,09 \%)\end{array}$ & $620(29,33 \%)$ & \multirow[b]{2}{*}{$<0,001$} \\
\hline & $\begin{array}{c}\text { Tỷ lệ theo } \\
\text { tổng bỏng } \\
\text { sâu }\end{array}$ & $34,0 \%$ & $55,1 \%$ & $2,0 \%$ & $8,8 \%$ & \\
\hline \multicolumn{2}{|c|}{ Chấn thương kết hợp } & $\begin{array}{c}57 \\
(1,7 \%)\end{array}$ & $\begin{array}{c}65 \\
(0,9 \%)\end{array}$ & 0 & $\begin{array}{c}17 \\
(0,8 \%) \\
\end{array}$ & $<0,001$ \\
\hline \multicolumn{2}{|c|}{ Bỏng hô hấp } & $\begin{array}{c}25 \\
(0,7 \%)\end{array}$ & $\begin{array}{c}489 \\
(6,4 \%)\end{array}$ & 0 & 1 & $<0,001$ \\
\hline
\end{tabular}


Nhận xét: Bỏng nhiệt khô, bỏng điện là nguyên nhân gây bỏng sâu nhiều nhất và cũng là nguyên nhân gây bỏng rộng nhất đối với cả diện tích bỏng chung và bỏng sâu. Đồng thời, bỏng nhiệt khô và bỏng điện có tỷ lệ chấn thương kết hợp hoặc bỏng hô hấp kèm theo cao nhất.

Bảng 3.5. Ngày điều trị theo các đặc điểm

\begin{tabular}{|c|c|c|c|}
\hline \multicolumn{2}{|r|}{ Đặc điểm } & Trung bình & $\mathbf{p}$ \\
\hline \multirow{2}{*}{ Giới tính } & $\operatorname{Nam}(\mathrm{n}=9.853)$ & $12(7-23)$ & \multirow{2}{*}{$<0,001$} \\
\hline & Nư $(n=3.608)$ & $11(7-22)$ & \\
\hline \multirow{2}{*}{ Nơi chốn } & Thành thị $(\mathrm{n}=3.721)$ & $11(7-21)$ & \multirow{2}{*}{$<0,001$} \\
\hline & Nông thôn $(n=9.740)$ & $12(7-23)$ & \\
\hline \multirow{2}{*}{$\mathrm{BHYT}$} & Có $(n=5.585)$ & $14(6-26)$ & \multirow{2}{*}{$<0,001$} \\
\hline & Không $(n=7.876)$ & $11(6-21)$ & \\
\hline \multirow{4}{*}{ Tác nhân } & Điện $(n=3.339)$ & $18(9-31)$ & \multirow{4}{*}{$<0,0001$} \\
\hline & Hóa chất $(n=348)$ & $10(5-21)$ & \\
\hline & Nhiệt khô $(n=7.860)$ & $12(7-21)$ & \\
\hline & Nhiệt ướt $(n=2.114)$ & $9(6-15)$ & \\
\hline \multirow{2}{*}{ Tuổi } & $16-30$ tuổi $(n=6.317)$ & $12(7-23)$ & \multirow{2}{*}{0,51} \\
\hline & $31-59$ tuổi $(n=7.144)$ & $12(7-23)$ & \\
\hline
\end{tabular}

Nhận xét: Bệnh nhân nam giới, bệnh nhân đến từ nông thôn và bệnh nhân có BHYT có ngày nằm điều trị dài hơn. Về tác nhân bỏng, bỏng do điện có số ngày điều trị dài nhất, sau đến bỏng do nhiệt khô.

Bảng 3.61. Kết quả điều trị theo các đặc điểm

\begin{tabular}{|c|c|c|c|c|}
\hline \multirow{2}{*}{\multicolumn{2}{|c|}{ Đặc điểm }} & \multicolumn{2}{|c|}{ Kết quả điều trị } & \multirow{2}{*}{ p } \\
\hline & & \multirow{2}{*}{$\begin{array}{c}\text { Sống } \\
9.324(94,63 \%)\end{array}$} & \multirow{2}{*}{$\begin{array}{c}\text { Tử vong } \\
529(5,37 \%)\end{array}$} & \\
\hline \multirow{2}{*}{ Giới tính } & $\operatorname{Nam}(n=9.853)$ & & & \multirow{2}{*}{$<0,001$} \\
\hline & $N u \tilde{~}(n=3.608)$ & $3.475(96,31 \%)$ & $133(3,69 \%)$ & \\
\hline \multirow{2}{*}{ Nơi chốn } & Thành thị $(\mathrm{n}=3.721)$ & $3.576(96,1 \%)$ & $145(3,90 \%$ & \multirow{2}{*}{0,001} \\
\hline & Nông thôn $(n=9.740)$ & $9.223(94,69 \%)$ & $517(5,31 \%)$ & \\
\hline \multirow{2}{*}{ BHYT } & Có $(n=5.585)$ & $5.351(95,81 \%)$ & $234(4,19 \%)$ & \multirow{2}{*}{0,001} \\
\hline & Không $(n=7.876)$ & $7.448(94,57 \%)$ & $428(5,43 \%)$ & \\
\hline \multirow{4}{*}{ Nguyên nhân } & Điện $(n=3.339)$ & $3.252(97,39 \%)$ & $87(2,61 \%)$ & \multirow{4}{*}{$<0,001$} \\
\hline & Hóa chất $(n=348)$ & $344(98,85 \%)$ & $4(1,15 \%)$ & \\
\hline & Nhiệt khô $(\mathrm{n}=7.860)$ & $7.316(93,08 \%)$ & $544(6,92 \%)$ & \\
\hline & Nhiệt ướt ( $\mathrm{n}=2.114)$ & $2.087(98,72 \%)$ & $27(1,28 \%)$ & \\
\hline \multirow{3}{*}{ Nhóm tuổi } & 16 - 30 tuổi $(n=6.317)$ & $6.092(96,44 \%)$ & $225(3,56 \%)$ & \multirow{2}{*}{$<0,001$} \\
\hline & $31-59$ tuổi $(n=7.144)$ & $6.707(93,88 \%)$ & $437(6,12 \%)$ & \\
\hline & Trung bình & \multicolumn{2}{|c|}{$33,7 \pm 11,1$} & \\
\hline \multirow{2}{*}{ Bỏng hô hấp } & Không $(n=12.946)$ & $12.671(97,9 \%)$ & $275(2,1 \%)$ & \multirow{2}{*}{$<0,001$} \\
\hline & Có $(n=515)$ & $128(24,9 \%)$ & $387(75,1 \%)$ & \\
\hline \multirow{2}{*}{$\begin{array}{l}\text { Chấn thương } \\
\text { kết hợp }\end{array}$} & Không $(n=13.322)$ & $12.676(95,2 \%)$ & $656(4,8 \%)$ & \multirow{2}{*}{0,001} \\
\hline & Có $(n=139)$ & $123(88,5 \%)$ & $16(11,5 \%)$ & \\
\hline Tổng & & $12.799(95,08 \%)$ & $662(4,92 \%)$ & \\
\hline
\end{tabular}


Nhận xét: Bệnh nhân bỏng người lớn có tỷ lệ tử vong chung là $4,92 \%$, nam giới có tỷ lệ tử vong cao hơn $(5,37 \%$ so với $3,69 \%$ nữ, $p<0,001$ có ý nghĩa thống kê). Bệnh nhân đến từ nông thôn chiếm tỷ lệ nhiều hơn thành thị $(5,31 \%$ so với $3,9 \%, p$ $=0,001)$. Bệnh nhân không có BHYT chiếm đa số $(5,43 \%$ so với $4,19 \%$ có BHYT, $p=$
0,001). Bệnh nhân nhóm tuổi cao tử vong nhiều hơn $(6,12 \%$ so với $3,56 \%, p<$ $0,001)$, đặc biệt cao ở bệnh nhân bị bỏng nhiệt khô $(6,92 \%, p<0,001)$, có chấn thương kết hợp $(11,5 \%, p=0,001)$. Tỷ lệ tử vong đặc biệt cao ở bệnh nhân bị bỏng hô hấp $(75,1 \%, p<0,001)$

Bảng 3.7. Kết quả điều trị theo diện tích bỏng

\begin{tabular}{|c|c|c|c|c|}
\hline & \multirow{2}{*}{ Diện tích bỏng } & \multicolumn{2}{|c|}{ Kết quả điều trị } & \multirow{2}{*}{$\mathbf{p}$} \\
\hline & & Sống & Tử vong & \\
\hline \multirow{5}{*}{$\begin{array}{l}\text { Bỏng } \\
\text { chung }\end{array}$} & Từ 0 - 19\% DTCT & $9.786(99,76 \%)$ & $24(0,24 \%)$ & \multirow{4}{*}{$<0,001$} \\
\hline & Từ 20 - 39\% DTCT & $2.199(97,84 \%)$ & $48(2,14 \%)$ & \\
\hline & Từ 40 - 59\% DTCT & $625(80,85 \%)$ & $148(19,15 \%)$ & \\
\hline & Từ 60\% DTCT trở lên & $189(29,95 \%)$ & $442(70,05 \%)$ & \\
\hline & LA50 & \multicolumn{2}{|c|}{$64,26 \%$} & \\
\hline \multirow{6}{*}{ Bỏng sâu } & Bỏng nông & $6.410(99,74 \%)$ & $17(0,26 \%)$ & \multirow{5}{*}{$<0,001$} \\
\hline & Dưới 10\% DTCT & $5.070(99,53 \%)$ & $24(0,47 \%)$ & \\
\hline & Từ 10 - 39\% DTCT & $1.228(83,42 \%)$ & $244(16,58 \%)$ & \\
\hline & Từ 40 - 59\% DTCT & $78(27,46 \%)$ & $206(72,54 \%)$ & \\
\hline & Từ 60\% DTCT trở lên & $13(7,07 \%)$ & $171(92,93 \%)$ & \\
\hline & LA50 & \multicolumn{2}{|c|}{$35,68 \%$} & \\
\hline
\end{tabular}

* LA50: Diện tích bỏng có 50\% bệnh nhân tử vong

Nhận xét: Tỷ lệ tử vong cao ở diện chung là $64,26 \%$. Bỏng sâu trên $60 \%$ tích bỏng rộng, bỏng sâu lớn. Diện tích DTCT tỷ lệ tử vong là $92,93 \%$, chỉ số LA50 bỏng chung trên $60 \%$ DTCT tỷ lệ tử vong là diện tích bỏng sâu là 35,68\%. $70,05 \%$, chỉ số LA50 của diện tích bỏng

Bảng 3.8. Phân tích đa biến mối tương quan của tỷ lệ tử vong với các yếu tố

\begin{tabular}{|l|c|c|c|c|c|c|}
\hline \multicolumn{1}{|c|}{ Đặc điểm } & B & S.E. & Wald & df & Sig. & Exp (B) \\
\hline Giới tính & 0,052 & 0,174 & 0,089 & 1 & $\mathbf{0 , 7 6 6}$ & 1,053 \\
\hline Nơi chốn & 0,342 & 0,177 & 3,740 & 1 & $\mathbf{0 , 0 5 3}$ & 1,408 \\
\hline BHYT & 0,407 & 0,146 & 7,717 & 1 & 0,005 & 1,502 \\
\hline Tuổi (năm) & 0,048 & 0,007 & 51,605 & 1 & 0,000 & 1,049 \\
\hline Bỏng hô hấp & 1,110 & 0,091 & 148,644 & 1 & 0,000 & 3,034 \\
\hline Chấn thương kết hợp & 1,290 & 0,453 & 8,098 & 1 & 0,004 & 3,631 \\
\hline Diện tích bỏng chung & 0,056 & 0,004 & 188,093 & 1 & 0,000 & 1,058 \\
\hline Diện tích bỏng sâu & 0,071 & 0,005 & 175,764 & 1 & 0,000 & 1,074 \\
\hline Constant & $-9,362$ & 0,605 & 239,557 & 1 & 0,000 & 0,000 \\
\hline
\end{tabular}


Nhận xét: Đưa các yếu tố ảnh hưởng đến tử vong theo phân tích đơn biến vào phân tích đa biến thấy tình trạng tử vong của bệnh nhân tương quan đa biến với các yếu tố: Tuổi, diện tích bỏng chung, bỏng sâu, có chấn thương kết hợp, bỏng hô hấp, có BHYT. Giới tính, nơi chốn không ảnh hưởng độc lập đến kết quả điều trị.

\section{BÀN LUÂN}

Nhiều nghiên cứu chỉ ra đặc điểm dịch tễ bệnh nhân bị bỏng ở các nước là khác nhau, đặc điểm bệnh nhân điều trị tại các trung tâm bỏng cũng khác nhau, khác nhau theo lứa tuổi, thành phần trong xã hội, và cũng thể hiện được $x u$ thế chung về tình hình bỏng của một quốc gia.

Nghiên cứu về bệnh nhân người lớn bị bỏng của chúng tôi cho kết quả: Bệnh nhân nam chiếm tỷ lệ $73,20 \%$, tỷ lệ Nam/Nữ = 2,73/1; bệnh nhân đến từ nông thôn nhiều hơn thành thị (nông thôn $72,36 \%$ và thành thị 27,64\%); bệnh nhân không có BHYT chiếm $58,51 \%$; bệnh nhân trong giai đoạn tuổi lao động chính chiếm tỷ lệ cao (20 - 29 tuổi chiếm $36,22 \%, 30$ - 39 tuổi chiếm $27,61 \%)$. Bỏng nhiệt khô và bỏng điện lần lượt là nguyên nhân gây bỏng nhiều nhất $(56,91 \%$ và $24,80 \%)$ (Bảng 3.1). Bệnh nhân có diện tích bỏng sâu chiếm $52,25 \%$. Diện tích bỏng trung bình là $9 \%$ (diện tích bỏng từ $3-20 \%$ ), diện tích bỏng sâu trung bình là $0-4 \%$. Có 515 bệnh nhân bị bỏng hô hấp chiếm $3,83 \%$, có chấn thương kết hợp chiếm 0,94\% (Bảng 3.2).

Bệnh nhân nam chiếm đa số, đến từ nông thôn là chủ yếu. Trong lứa tuổi lao động, nam giới và người đến từ nông thôn có nguy cơ bị bỏng cao hơn, do làm các công việc nặng nhọc liên quan cháy nổ và liên quan đến điện. Thể hiện ở tỷ lệ bệnh nhân bỏng nhiệt khô như lửa, bỏng kim loại nóng, bỏng điện chiếm ưu thế. Nó cũng thể hiện ở những ngành nghề chủ yếu ở lĩnh vực có nguy cơ cao (công nhân, nông dân, tự do). Bỏng cũng tập trung ở độ tuổi lao động chính, phù hợp với các đặc điểm trên (từ 20 - 39 tuổi). Phân tích cho thấy bỏng nặng cao hơn ở bệnh nhân đến từ nông thôn, nam giới bị là chính, đặc biệt do bỏng nhiệt khô và bỏng điện.

Nghiên cứu này có kết quả phù hợp một số nghiên cứu trước đây, theo Trần Đoàn Đạo (2015), khoa Bỏng - bệnh viện Chợ Rẫy trong 3 năm từ năm 2012 đến 2014 đã điều trị 2818 bệnh nhân; trong đó nam chiếm $67,42 \%$, nữ chiếm $32,58 \%$, tỷ lệ nam/nữ xấp xỉ $2 / 1$, bỏng nặng chiếm tỷ lệ $30,44 \%$, bỏng trung bình có tỷ lệ $33,96 \%$, Bỏng do nhiệt (Khô, Ướt) chiếm tỷ lệ $60,82 \%$, Bỏng điện có tỷ lệ 37,82\% [2].

Theo Ortiz-Prado và cộng sự (2015), nghiên cứu bỏng ở người lớn ở Ecuador từ 2005 đến 2014 nam chiếm 69,37\% với 768 trường hợp và nữ chiếm $30,62 \%$ với 337 bệnh nhân. Bỏng do nhiệt chiếm 65,78\%, tiếp theo là bỏng điện với $30,53 \%$, bỏng do tiếp xúc chiếm $2,06 \%$ và bỏng do hóa chất chiếm 1,62\%. Nhóm nghề nghiệp bị ảnh hưởng nhiều nhất là công nhân xây dựng và những người ở nhà [3].

Trong nghiên cứu của Wang và cộng sư (2018) trong 10 năm thấy đặc điểm của người lớn bị bỏng khác trẻ em, trẻ em với độ tuổi trung bình người lớn trung bình là $42,48 \pm 14,76$ tuổi. Số trẻ em nam bị bỏng nhiều hơn 1,6 lần và nam bị bỏng nhiều hơn 2,3 lần so với nữ và tỷ lệ bị bỏng ở nam giới trưởng thành cao hơn $(p=0,020)$. Căn nguyên ở người lớn rất đa dạng, nguyên nhân chính là các yếu tố liên quan đến lửa, sau đó là điện $(p<0,001)[4]$.

Tại Canada, một nước phát triển đã tổng kết bỏng ở người lớn trong 40 năm (từ năm 1976 - 2015) của Nickel và cộng 
sự (2020) thấy, tỷ lệ nam/nữ là $3,1 / 1$ $(75,8 \% / 24,2 \%)$, bỏng do lửa là $78,8 \%$, do chất lỏng nóng là $16,8 \%$, điện là $1,6 \%$, tiếp xúc vật nóng là $2,85 \%$, do hóa chất là $0,3 \%[5]$.

Theo Seo và cộng sự (2015), tại Hàn Quốc trong 10 năm 2003 đến 2012, nghiên cứu 4481 bệnh nhân bỏng nặng được điều trị tại trung tâm bỏng có tỷ lệ nam/nữ là $2,88 / 1$; Bỏng do lửa là $67,3 \%$, bỏng nhiệt là $22,0 \%$, bỏng điện $7,5 \%$, do hóa chất $1,6 \%$ và tiếp xúc $1,5 \%$. Diện tích bỏng trung bình là $35,1 \% \pm 24,4 \%$, diện tích bỏng sâu trung bình là $20,6 \% \pm 25,6 \%$ [6].

Trong nghiên cứu của lqbal và cộng sự năm 2013 nghiên cứu 13.295 bệnh nhân trong khoảng thời gian 2 năm tại Trung tâm chăm sóc Bỏng, Viện Khoa học $Y$ tế Pakistan thấy, có $7.503(56,43 \%)$ nam và $5.792(43,56 \%)$ nữ. Độ tuổi trung bình của người lớn là $33,63 \pm 10,76$ tuổi. Bỏng do nhiệt phổ biến nhất $(42,48 \%)$, tiếp theo là bỏng lửa (39\%) và bỏng điện $(9,96 \%)$, diện tích bỏng trung bình là $10,64 \% \pm 11,45 \%$, bệnh nhân bỏng hô hấp chiếm 1,12\% [7],

Như vậy, trong nghiên cứu của chúng tôi, tỉ lệ giới tính các bệnh nhân bị bỏng, tỷ lệ bỏng hô hấp tương đồng với các nước trong khu vực và trên thế giới, tỷ lệ nguyên nhân có khác so với các nước, có lẽ do cơ cấu nghề nghiệp, do điều kiện kinh tế, xã hội khác nhau.

Ngày điều trị và tình hình tử vong là các yếu tố đánh giá chất lượng và kết quả điều trị, phân tích các nội dung này chúng tôi thấy: Thời gian điều trị trung bình của bệnh nhân người lớn là 12 ngày (số ngày điều trị từ 7 - 20 ngày). Ngày nằm điều trị kéo dài hơn ở nam giới, bệnh nhân đến từ nông thôn, đây là những đối tượng có yếu tố nguy cơ cao bị bỏng nặng nên ngày nằm diều trị dài hơn.
Kết quả nghiên cứu của chúng tôi tương đồng với số ngày nằm trung bình của bệnh nhân bỏng trong nghiên cứu của Trần Đoàn Đạo (2015): Năm 2012 là 18,1 ngày; năm 2013 là 17,7 ngày và năm 2014 là 15,9 ngày [2], có lẽ mô hình bệnh tật thu dung và điều kiện điều trị 2 cơ sở là tương đương nhau.

Theo Ortiz-Prado và cộng sự, nghiên cứu bỏng ở người lớn ở Ecuador tròn 10 năm: Tỷ lệ tử vong chung là $10,2 \%$ và thời gian nằm viện trung bình là 23 ngày [3].

Trong nghiên cứu của Wang và cộng sự (2018) cho thấy, ngày nằm điều trị bỏng trung bình của người lớn là 12 ngày (số ngày điều trị từ 6 - 27), diện tích bỏng, mức độ bỏng và các biến chứng (bao gồm sốc, tổn thương cơ quan và nhiễm trùng vết thương) ảnh hưởng đến ngày nằm điều trị, yếu tố làm giảm ngày nằm điều trị LOS là tuổi $(H R=0,993$, Cls: 0,988 - 0,997) và việc sử dụng phương pháp ghép da $(\mathrm{HR}=$ 0,339, Cls: $0,254-0,451)$. Ngược lại, các yếu tố làm tăng ngày nằm điều trị là giới tính nam (HR = 1,234, Cls: 1,026 - 1,484), bỏng nông ( $H R=3,128$, Cls: 2,349 4,166), bỏng sâu (HR = 1,791, Cls: 1,379 2.327 ), diện tích bỏng từ $10 \%$ đến $29 \%$ $(\mathrm{HR}=3.978$, Cls: $2,551-6,205)$ và nguyên nhân nhiệt so với không do nhiệt (HR = 1,497). Sự gia tăng diện tích bỏng khiến vết thương tiết dịch nghiêm trọng hơn. Điều này làm xáo trộn môi trường bên trong vết thương và các hệ thống khác bị tổn thương. Tình trạng bệnh phức tạp hơn và người bệnh cần điều trị trong thời gian dài. Hơn nữa, diện tích da bị tổn thương càng lớn thì thời gian liền da càng lâu. Căn nguyên nhiệt là một yếu tố nguy cơ ( $\mathrm{HR}=$ $1,497)$ có thể bởi vì tổn thương nhiệt không chỉ do tiếp xúc trực tiếp với da mà còn làm tổn thương mô sâu [4].

Theo nghiên cứu Li và cộng sự (2017) chỉ ra, ngày nằm trung bình các bệnh nhân 
bỏng là 17 ngày, các yếu tố kéo dài ngày nằm điều trị là diện tích bỏng chung và sâu lớn, tuổi cao, bỏng do lửa, điện, nổ và do tiếp xúc [8]. Tương tự như trong nghiên của của Ye và cộng sự (2016), nghiên cứu trên bệnh nhân bỏng hóa chất trong 10 năm, ngày nằm trung bình là $17,0 \pm 23,1$ [9].

Một nghiên cứu sâu hơn của Wardhana và cộng sự (2017), nghiên cứu dịch tễ bỏng ở Indonesia trong 3 năm (từ năm 2013 - 2015) thấy, ngày nằm viện trung bình của bệnh nhân bỏng là 11 ngày [10]. Cũng như nghiên cứu của Elsous và cộng sự (2017) tại dải Gaza thấy ngày nằm viện trung bình là 11,45 ngày [11].

Về tử vong, trong nghiên cứu này có 662 bệnh nhân tử vong trong 13.641 bệnh nhân nghiên cứu, chiếm tỷ lệ là $4,92 \%$. Tử vong theo các đặc điểm thấy có sự khác biệt về tỷ lệ tử vong theo giới, theo địa lý, theo nguyên nhân gây bỏng, theo mức độ bỏng $(p<0,05)$, Theo mức độ bỏng, chủ yếu bệnh nhân quân tử vong có mức độ bỏng khi vào viện đều là nặng. Đặc biệt bỏng theo tác nhân, tỷ lệ tử vong cao nhất là do bỏng nhiệt khô là $6,92 \%$ sau đó đến bỏng điện, tỷ lệ này cao ở những ngành nghề có yếu tố nguy cơ bỏng nhiệt khô cao như nông dân, đầu bếp $(p<0,001)$. Tỷ lệ tử vong đặc biệt cao hơn ở nhóm có chấn thương kết hợp $(75,1 \%$ so với $2,1 \%, p<$ $0,001)$ và bỏng hô hấp $(11,5 \%$ so với $4,8 \%$, $p=0,001)$. Tử vong theo diện tích bỏng chung và bỏng sâu thấy có sự khác biệt giữa các nhóm diện tích $(p<0,05)$, diện tích bỏng chung, bỏng sâu tăng thì tỷ lệ tử vong tăng (bảng 3.7). Tăng cao ở bệnh nhân bỏng chung từ $40 \%$ trở lên, bỏng sâu từ $10 \%$ trở lên. Chỉ số LA50 của bỏng chung là $64,26 \%$, LA50 bỏng sâu là $35,68 \%$.

Lứa tuổi người lớn, chúng ta thường quan tâm đến các tác nhân bỏng, vì đây là các nguy cơ khác so với lứa tuổi trẻ em và người già. Qua phân tích thấy bỏng điện và nhiệt khô là tác nhân có tỷ lệ bỏng nặng, bỏng sâu cao nhất, nó cũng là tác nhân gây bỏng diện tích cao hơn cả về bỏng chung và bỏng sâu. Bỏng nhiệt khô và bỏng điện là tác nhân có tỷ lệ chấn thương kết hợp và bỏng hô hấp cao nhất. Chính vì vậy, tỷ lệ tử vong do các tác nhân này cao hơn hẳn.

Tỷ lệ tử vong trong nghiên cứu này thấp hơn tỷ lệ tử vong ở bệnh nhân do tai nạn lao động trong nghiên cứu của Nguyễn Tiến Dũng và cộng sự (2012) khi nghiên cứu (tî̉ lệ tử vong là 10,55 \%) [12]. Tỷ lệ tử vong phụ thuộc vào tuổi và yếu tố nghề nghiệp, phù hợp với các nghiên cứu trên thế giới. Tỷ lệ tử vong trong nghiên cứu của chúng tôi cao hơn trong một số nghiên cứu ở các nước trong khu vực. Trong nghiên cứu của lqbal và cộng sự (2013) là 1,48 [7]. Các nghiên cứu có đối tượng là các bệnh nhân ở mọi lứa tuổi. Nhiều nghiên cứu cho kết quả cao hơn, theo nghiên cứu của Ortiz-Prado và cộng sự (2015), nghiên cứu bỏng ở người lớn ở Ecuador tỷ lệ tử vong chung là 10,2\% [3]. Tỷ lệ này ở Canada là 7,7\% [5].

Khi phân tích đa biến mối tương quan của tỷ lệ tử vong ở bệnh nhân với các đặc điểm cho thấy, tương quan với các yếu tố tuổi, diện tích bỏng chung, bỏng sâu, bỏng hô hấp, chấn thương kết hợp, có BHYT (bảng 3.8). Giới tính và nơi chốn không phải là các yếu tố độc lập ảnh hưởng đến tử vong.

Kết quả nghiên cứu của chúng tôi phù hợp với các nghiên cứu trong nước và trên thế giới, Nguyễn Tiến Dũng và cộng sự (2012) khi nghiên cứu các yếu tố tiên lượng tử vong ở bệnh nhân bỏng do tai nạn lao động: Các yếu tố tiên lượng tử vong là bỏng đường hô hấp, hồi sức dịch thể không đúng, sốc bỏng nặng, diện tích 
bỏng sâu lớn hơn 20\%, glucose máu tăng cao khi nhập viện [12].

Theo báo cáo tổng kết bỏng 40 năm ở Canada, Nickel và cộng sự (2020) thấy các yếu tố ảnh hưởng đến tỷ lệ tử vong bỏng người lớn bao gồm: Tăng thời gian lưu trú, tuổi và diện tích bỏng, giới tính nam và số biến chứng [5].

Trong nghiên cứu của Li và cộng sự (2017 ) cho rằng diện tích bỏng chung, bỏng sâu và tuổi là các yếu tố liên quan đến tử vong [8]. Năm 2016, Hwee và cộng sự nghiên cứu ở Hàn Quốc chỉ ra nguyên nhân gây tử vong chính là bỏng hô hấp, nhiễm khuẩn huyết và diện tích bỏng trên 20\% diện tích cơ thể [13]. Năm 2015, Seo cho rằng giới nữ, bỏng hô hấp, tổng diện tích bỏng sâu, bỏng chung lớn và tuổi là các yếu tố dự đoán tử vong [6].

\section{KẾT LUẬN}

Còn nhiều thách thức trong điều trị bỏng, đặc biệt bỏng nhiệt khô và điện là những tác nhân chủ yếu gây bỏng ở người lớn, gây bỏng rộng, bỏng sâu, bỏng nặng, bỏng hô hấp, tỷ lệ chấn thương kết hợp cao. Tác nhân này khiến bỏng ở người lớn nằm điều trị dài ngày hơn, tỷ lệ tử vong cao. Ngoài ra vấn đề bệnh nhân không có BHYT cũng ảnh hưởng đến kết quả điều trị với tỷ lệ tử vong cao hơn.

\section{TÀI LIÊU THAM KHẢO}

1. Wald, D. (2012). Burns. In S. Mahadevan \& G. Garmel (Eds.), An Introduction to Clinical Emergency Medicine (pp. 207-220). Cambridge: Cambridge University Press. doi:10.1017/CBO9780511852091.022.

2. Trần Đoàn Đạo (2015), Tình hình điều trị bỏng và di chứng bỏng tại bệnh viện Chợ Rấy trong 3 năm 2012 - 2014. Y học thảm họa và Bỏng.2/2015: 25-29.

3. Ortiz-Prado E., Armijos L. and Iturralde A. L. (2015), A population-based study of the epidemiology of acute adult burns in Ecuador from 2005 to 2014. Burns.41 (3): 582-589.

4. Wang T., Nie C., Zhang H.. et al (2018), Epidemiological characteristics and factors affecting length of hospital stay for children and adults with burns in Zunyi, China: a retrospective study. PeerJ.6: e5740.

5. Nickel K. J., Omeis T. and Papp A. (2020), Demographics and clinical outcomes of adult burn patients admitted to a single provincial burn center: A 40-year review. Burns.

6. Seo D. K., Kym D., Yim H.. et al (2015), Epidemiological trends and risk factors in major burns patients in South Korea: a $10-$ year experience. Burns.41 (1): 181-187.

7. Iqbal T., Saaiq M. and Ali Z. (2013), Epidemiology and outcome of burns: early experience at the country's first national burns centre. Burns.39 (2): 358-362.

8. Li H., Yao Z., Tan J.. et al (2017), Epidemiology and outcome analysis of 6325 burn patients: a five-year retrospective study in a major burn center in Southwest China. Scientific reports.7: 46066.

9. Ye C., Wang X., Zhang Y.. et al (2016), Ten-year epidemiology of chemical burns in western Zhejiang Province, China. Burns.42 (3): 668-674.

10. 10. Wardhana A., Basuki A., Prameswara A. D. H.. et al (2017), The epidemiology of burns in Indonesia's national referral burn center from 2013 to 2015. Burns Open.1 (2): 67-73.

11. 11. Elsous A., Ouda M., Mohsen S.. et al (2016), Epidemiology and outcomes of hospitalized burn patients in Gaza Strip: a descriptive study. Ethiopian Journal of health sciences.26 (1): 9-16.

12. Nguyễn Tiến Dũng và Nguyễn Như Lâm (2012), Nghiên cứu các yếu tố tiên lượng tử vong ở bệnh nhân bỏng do tai nạn lao động. Tạp chí y học Thảm họa và Bỏng.12012.

13. Hwee J., Song C., Tan K. C.. et al (2016), The trends of burns epidemiology in a tropical regional burns center. Burns.42 (3): 682-686. 